\title{
"De primeiro não era assim": histórias, paisagens e as coisas da Ilha do Pará, Afuá, Amazônia
}

Queiton Carmo dos Santos*

SANTOS, Q. C. "De primeiro não era assim": histórias, paisagens e as coisas da Ilha do Pará, Afuá, Amazônia. R. Museu Arq. Etn. 36: 109-126, 2021.

Resumo: A partir da arqueologia etnográfica, esse estudo busca evidenciar como as pessoas que habitam o distrito de Afuá, a Ilha do Pará, uma região de fronteira fluvial da foz do Rio Amazonas, se relacionam com suas paisagens, lugares e suas coisas e como, através desses elementos, elaboram narrativas a respeito de seus tempos. Assim, o artigo pretende tensionar o entendimento e as práticas relativas ao campo disciplinar arqueológico por meio dos saberes locais e das presenças arqueológicas e, dessa maneira, contribuir para atuais discussões que provocam uma relação estreita entre estudos etnográficos e a arqueologia na e da Amazônia.

Palavras-chave: Arqueologia; Etnografia; Coisas; Histórias; Amazônia.

\section{Iniciando a conversa}

A Amazônia é um lugar ambivalente tanto para o Brasil como para o "exterior". É uma zona pouco compreendida pelos seus próprios conhecimentos localizados o que a permite ser produzida ontoepistemologicamente por outras pessoas e instituições não amazônicas.

A continuidade desse pensamento performa uma continuidade do olhar colonial. Nesse texto, não tenho a intenção de falar da totalidade de um conhecimento amazônico visto de distintas perspectivas, mas parto do entendimento de que sua posicionalidade deve ser cada vez mais discutida, evitando a continuidade de um pensamento com práticas colonialistas.

Nas palavras de Chimamanda Adichie (2019), contar uma história única é um perigo

* Mestre pelo Programa de Pós-Graduação em Arqueologia e Antropologia pela Universidade Federal de Minas Gerais. <tonqueiton@gmail.com> que corremos muitas vezes de modo consciente ou inconscientemente, em especial, nas "disciplinas" que lidam com a produção de temporalidades não ocidentais, como é o caso da arqueologia. Procuro aqui me afastar desse risco ao me basear no diálogo proposto por Gabby Hartemann e Irislane Moraes (2018), para quem contar histórias e caminhar com os ancestrais são maneiras de pensar tanto a arqueologia e como outras perspectivas de conhecimentos que possam ir além do convencional com a qual a disciplinaridade está limitada à interagir.

Esse artigo se constitui em um suporte reflexivo oriundo da minha atual pesquisa na Ilha do Pará, em comunidades convencionalmente chamadas de ribeirinhas na Amazônia brasileira. Ele é propositalmente localizado e parcial, logo, restrito ao tempo que o escrevo, mas não fechado nele. A Ilha do Pará (Fig. 1) é um distrito pertencente ao município de Afuá formado por um conjunto de comunidades interioranas situadas no estuário 
"De primeiro não era assim": histórias, paisagens e as coisas da Ilha do Pará, Afuá, Amazônia

R. Museu Arq. Etn., 36: 109-126, 2021.

amazônico, a foz do rio Amazonas, e que estão em uma área de fronteira fluvial entre o estado do Amapá e o Pará. Por se localizarem nesse interflúvio, mesmo habitando oficialmente no
Pará, os habitantes da ilha estabelecem relações frequentes com a costa do Amapá devido às constantes viagens para os municípios de Santana e Macapá.

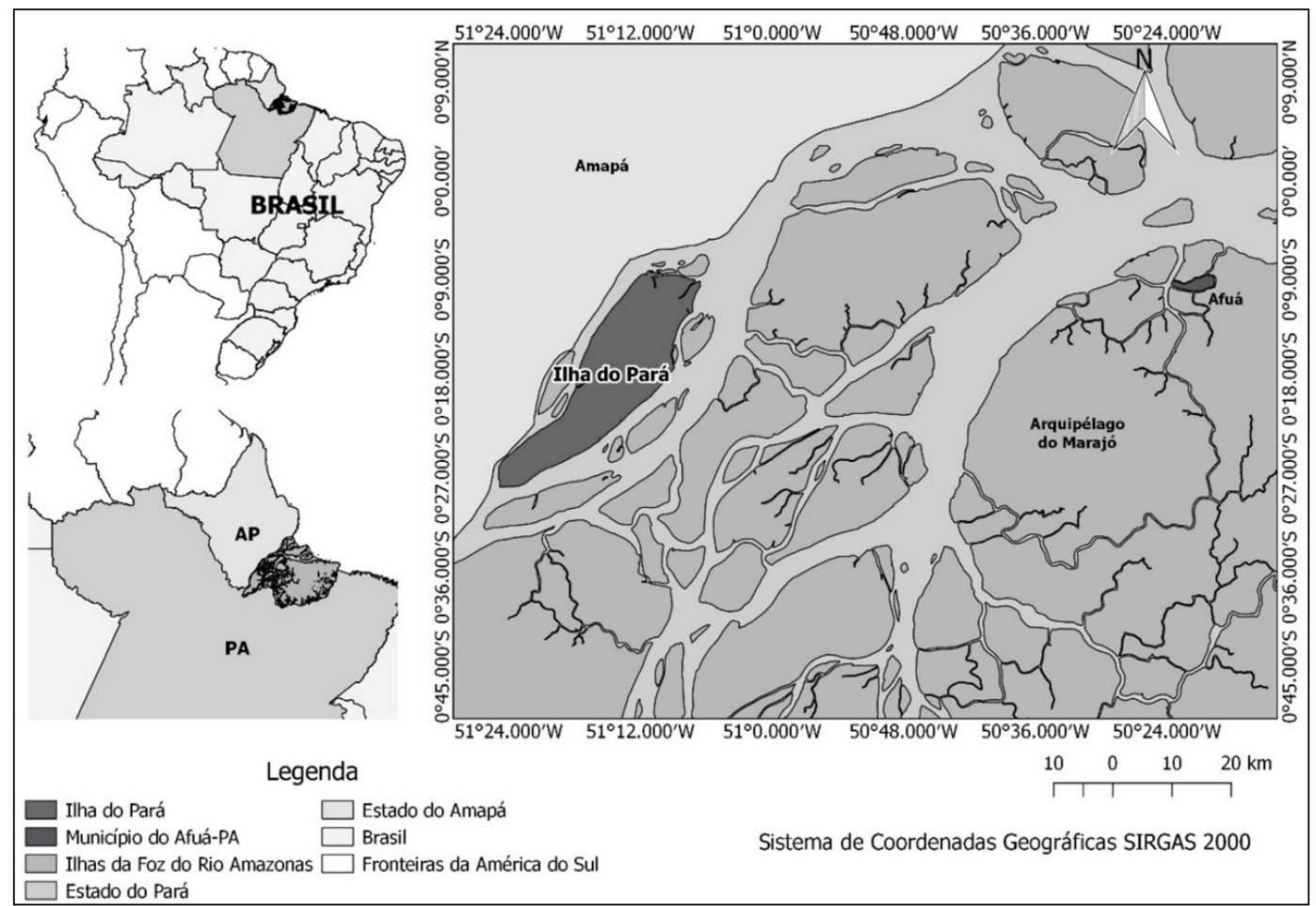

Fig. 1. Mapa de localização da Ilha do Pará, município de Afuá, estado do Pará - Brasil.

Fonte: elaboração própria, a partir de IBGE (2017-2019).

O município de Afuá pertence à grande Ilha do Marajó; segundo o último censo do Instituto Brasileiro de Geografia e Estatística (2010), a cidade contava com uma população total em torno de trinta e cinco mil pessoas. Na parte ocidental sul da ilha ${ }^{2}$, existem cerca de quinze comunidades identificadas conforme o nome do rio que habitam ou do santo padroeiro da localidade: Maniva, Cutias, Palhas, Arangona, Samuminha, Rio Furo Seco, Rio Água Preta, São Sebastião, Francisco Luiz, São Raimundo, Rio Samaúma, Rio Três Irmãos, Forta Fênix, entre outras. As e os habitantes das comunidades

2 Utilizarei em algumas passagens desse texto a palavra ilha para me referir à Ilha do Pará. do Rio Furo Seco, Água Preta e Arangona giram em torno de duas mil pessoas. Essas são as comunidades com as quais tenho uma relação direta, a partir da qual desenvolvo esta pesquisa.

Sou descendente dos moradores da Ilha do Pará, e mesmo não morando nela por longos períodos, foi a partir desse meu lugar social que surgiu o modo por meio do qual penso essa pesquisa. Atualmente possuo primos e tios que vivem na ilha, e meus pais e meus avôs nasceram e cresceram nela. Por isso, possuo uma relação de proximidade na maioria das minhas interpretações sobre os seus saberes locais. Aqui, o meu lugar como descendente, pesquisador e também autor opera de modo situacional na interação com as pessoas da ilha, 
a fim de levantar distintos modos de relações e reflexividades pessoais e ancestrais (Engmann 2019; Hartemann 2019).

Em suma, as pessoas que habitam a ilha vivem da extração do açá, da pesca, da caça e de outros produtos advindos da floresta ${ }^{3}$, os quais são geralmente comercializados no estado do Amapá. Como a maioria dos transportes nessa parte da Amazônia é feita por meio fluvial, os moradores transitam e realizam suas atividades cotidianas por meio de embarcações de médio e pequeno porte conhecidas como lanchas, catraios, canoas e rabetas.

Os registros das culturas arqueológicas amazônicas, por meio de vestígios pré-coloniais advindos das atuais regiões tanto no Amapá quanto no Pará, vêm demonstrando a existência de culturas e de fluxos de relações cada vez mais intensos na região do denominado platô das Guianas e em grande parte da calha do Rio Amazonas ${ }^{4}$. Ademais, a ilha compõe o arquipélago de ilhas da foz do Rio Amazonas, possivelmente um lugar de trânsito intenso de pessoas desde o período pré-colonial. Essa região foi alvo de buscas arqueológicas ocorridas durante o final do século XIX por naturalistas e seus colaboradores (Goeldi 1900; Guedes 1898) que tinham o intuito de coletar material arqueológico para a montagem de coleções museais.

Dos pontos de vista histórico e antropológico, há trabalhos desenvolvidos desde a década de cinquenta sobre comunidades ribeirinhas amazônicas, como o de Charles Wagley (1957), que investigou o pressuposto de comunidade amazônica, debatendo as questões de vida nos trópicos. $\mathrm{O}$ tema do desenvolvimento do "homem e o ambiente" também foi fortemente debatido durante décadas sucessoras na implementação dos primeiros projetos arqueológicos na Amazônia, como nas pesquisas de Evans \& Meggers (1950). Anos mais tarde, emergiram outras abordagens que

3 Apesar de outros produtos industrializados vindos da cidade, como frango, linguiça, mortadela e carne bovina, fazerem parte da circulação de alimentação local.

4 Para uma síntese com foco na cerâmica da região, ver: Barreto, Lima \& Betancourt (2016). também apresentavam essas comunidades como "caboclas" (Murrieta et al. 1999). Vale lembrar que, apesar de poucas vezes adotado, tal etnônimo não é considerado entre as próprias comunidades rurais amazônicas como detentor de uma legitimidade identitária política ${ }^{5}$.

$\mathrm{Na}$ arqueologia contemporânea, um dos trabalhos que propicia diálogo com a abordagem aqui proposta é o de Juliana Machado (2011). A arqueóloga brasileira teve o intuito de compreender a relação de ocupação das comunidades tradicionais ribeirinhas que habitam as margens dos rios na Ilha de Caviana. Em suas abordagens, Machado constatou que os conceitos de continuidade e de ruptura devem ser compreendidos pelas pesquisas arqueológicas, históricas e antropológicas ao lidarem com a formação, o modo de vida e as identidades amazônicas. A autora ressalta que a continuidade e o passado na Amazônia são carregados de mudanças e que estão entrelaçados de maneira dialética. Sendo assim, o impacto dessa constatação deveria também estar presente no registro arqueológico e na maneira que arqueólogos lidam com a relação direta entre presente etnográfico e o passado das sociedades que estudam (Machado 2009, 2014).

Para além dessa discussão inicial, pretendo neste texto compreender como as pessoas que habitam a Ilha do Pará, Afuá/PA, relacionam-se com seus lugares e suas coisas, ambos campos de estudos da arqueologia, bem como questionar como elaboram e contam seu passado por meio das coisas materiais. Nesse sentido, intenciono apresentar um esforço interpretativo a partir da minha experiência baseada na relação entre arqueologia e etnografia (Castañeda 2008; Hamilakis 2009; Hamilakis \& Anagnostopoulos 2009). Dessa maneira, busco contribuir para atuais discussões práticas e teóricas que provocam uma relação estreita entre estudos etnográficos e arqueológicos na e da Amazônia. Provocado a repensar a atmosfera dos aparatos convencionais do que chamamos de disciplina arqueológica, intento pensar a partir de outras formas de saberes e não somente do arqueológico ocidental.

5 Sobre a discussão do conceito de caboclo, ver: Lima (1999). 
Ao me questionar sobre a possibilidade de uma prática arqueológica pensada a partir dos conhecimentos locais, apresento um olhar dinâmico para as capacidades de compreensão de formas de interpretação daquilo que aceitamos como artefato ou sítio arqueológico. Pensar nessas formas de interpretação e interação, como entendido por Márcia Bezerra (2017, 2018), é refletir a respeito das "coisas que vazam", compreender múltiplas narrativas, encantadas e encantadoras, pelas quais a arqueologia pouco tem se interessado (Bezerra 2018).

Permeado por essas noções, trato aqui de alguns temas discutidos na arqueologia por meio da chamada virada ou giro etnográfico, como definido por Quetzil Castañeda (2008), e me relaciono com as esferas de saber e conhecer de maneira situacional e localizada, nos termos sobre conhecimentos situados propostos por Donna Haraway (1995). Desse modo, acompanho o que foi salientado por Mariana Petry Cabral (2014, 2016) ao pensar a arqueologia como possibilidade de criar pontes de conhecimentos, isto é, de relacionar distintas maneiras de conhecer com uma diversidade de mundos.

\section{Repensando paisagens e lugares, deslocando o olhar}

A paisagem não constitui um universal, ela é historicamente posicionada. Isso significa que ela existe fisicamente no decorrer do tempo, mas é postulada de significados quando coabitada com diferentes sujeitos. Essa é a observação levantada por Johnston para a arqueologia, na qual ele entende que o uso de paisagem deve ser pensado de maneira crítica ao postular que a "paisagem é o meio humano e o territorial, que é determinante do ambiente, ou seja, um parasita semiológico que alimenta padrões de metáfora, por exemplo, para a criação de vida social" (Johnston 1998: 315; tradução nossa).

6 Márcia Bezerra elabora essa discussão com base nos debates propostos pelo antropólogo britânico Tim Ingold, nos quais ele descreve a categoria das coisas transbordadas e vazadas como composições do fluxo (ou malhas) da vida (Ingold 2012, 2015)
Do mesmo modo, para o geógrafo brasileiro Luiz Otávio Cabral (2000: 37) a paisagem é uma percepção "atuante de parte de um espaço mais vasto que me é fornecido pela experiência direta (íntima) ou indireta (conceitual e simbólica)". Nesse sentido, o autor indica haver um reconhecimento pela paisagem do espaço, entendido este de modo distinto da ideia de lugar: o espaço seria apenas um vetor de garantia da paisagem em sua unicidade (Cabral 2000).

No que toca as distinções entre lugar e espaço, os lugares são definidos por Michel de Certeau (1998) como "a ordem (seja qual for) segundo a qual se distribuem relações de coexistência [...] Um lugar é, portanto, uma configuração instantânea de posições. Implica indicação de estabilidade" (Certeau 1998: 201). Em contrapartida, o espaço é delineado pelo mesmo autor como um "lugar praticado", "efeito produzido pelas operações que o orientam, o circunstanciam, o temporalizam e o levam a funcionar em unidade polivalente de programas conflituais ou de proximidades contratuais" (Certeau 1998: 202).

Crítica tanto da noção de espaço quanto da de tempo ocidental, a intelectual maori Linda Tuhiwai Smith (2018), em seu livro Descolonizando Metodologias, enfatiza que para algumas línguas indígenas não existe uma total distinção entre os dois conceitos. Ela exemplifica que em maori tempo e espaço são a mesma palavra: "Existem posições no tempo e no espaço em que eventos e pessoas estão situados, mas estas não podem necessariamente ser descritas como categoriais distintas de pensamento" (Tuhiwai Smith 2018: 66)

Do ponto de vista da geografia ${ }^{7}$, uma abordagem da paisagem mais alinhada com um pensamento conceitual designado de "geografia humanista" foi postulada principalmente pelos estudos de Yi-Fu Tuan (1983) ao conceitualizar o lugar como ligado às percepções de cada sociedade com o seu ambiente. Nesse sentido, no Brasil, o geógrafo Milton Santos

7 Convencionalmente, pensar arqueologias em relação com as formulações de lugares em seus amplos conhecimentos atuais merece uma posição de entendimento da própria geografia, área que há algum tempo realiza esse debate. 
(2006: 39-40) postulou que a "configuração territorial, ou configuração geográfica, tem, pois, uma existência material própria, mas sua existência social, isto é, sua existência real, somente lhe é dada pelo fato das relações sociais". A partir desses contextos, podemos compreender os lugares e suas paisagens como existências sociais; para além de sua fisicalidade, eles nos apontam para uma vasta discussão filosófica e teórica, que é percebida nas vivências com o mundo prático ${ }^{8}$.

Além disso, a relação de aproximação, de modo resumido, entre geografia e arqueologia foi descrita e apontada por Ana Cristina de Souza (2005), ao afirmar que as questões em torno das ideias de significado, simbolismos, subjetividades e materialidades "romperam com as tradicionais análises que, até então, permitiam distinguir os métodos de inferência utilizados por estas disciplinas" (Souza 2005: 294). Ao mesmo tempo, vale ressaltar que, segundo ela, as abordagens permeadas nesses campos se originam da teoria social, filosofia e mesmo da antropologia (Souza 2005).

$\mathrm{Na}$ antropologia, Johnston (1998) alertou que, para os estudos das "sociedades tradicionais", há uma dificuldade de tradução da paisagem entendida contemporaneamente para a de outros tempos passados. Sobre essa implicação, ele ressaltou que "há uma discussão sobre como essas ideias podem ser relacionadas à experiência humana no passado, mas essa discussão geralmente usa a paisagem como um quadro de referência." (Johnston 1998: 315; tradução nossa). Dessa maneira, existiria uma suposta estabilidade na interpretação do sentido em diferentes tempos e de diferentes pessoas, o que é criticado

8 Para um histórico dessas relações filosóficas, práticas e políticas que a geografia começou a estabelecer com outras disciplinas, ver Eduardo Marandola Jr. (2013). O autor buscou apresentar uma história ou historiografia da disciplina em que postulava uma relação com o campo emergente da fenomenologia, fortemente visível durante os anos 1970 e, atualmente, com a pós-fenomenologia. Esse momento pós-fenomenológico poderia ser entendido a partir da ideia de que se pretende "problematizar aspectos não resolvidos pela fenomenologia, especialmente quando se pensa nas transformações sociais e nas novas formas de sociabilidade contemporânea” (Marandola Jr. 2013: 58). justamente por criar um paradoxo9, visto que "a distinção é feita entre o mundo construído (a arqueologia) e o mundo natural (o território), assegurando uma relação empírica e mecanicista apenas entre os dois domínios da existência" (Johnston 1998: 316; tradução nossa).

Desse modo, a paisagem é um elemento totalizante de entendimento dos fenômenos que carrega temporalidades complexas, narrativas pessoais e coisas localizadas. De fato, os usos da paisagem devem ser entendidos contextualmente, sem que se perca de vista as críticas e o seu entendimento conceitual, bem como o próprio significado dos lugares para as pessoas que deles usufruem e nos quais criam suas vidas. No avançar dos debates interpretativos, mais recentemente a abordagem de Tim Ingold (2015) tem feito uma proposição de mudança conceitual da ideia postulada de paisagem para o que ele defendeu como mundostempos ou climas. Pois, é a partir da compreensão da paisagem, ou desses mundos-tempos, que tanto somos criados como criamos lugares, ao percebermos a relação intrínseca das relações vividas com o ambiente.

No entanto, como já nos alertou Linda Tuhiwai Smith (2018), nem sempre tempo e espaço são categorias distintas; pelo contrário, eles são complementares e relacionais para muitas populações indígenas e tradicionais em seus sentidos mais plurais e dinâmicos. Pois, como tem sido chamada a minha atenção pelas moradoras e moradores da Ilha do Pará, as coisas sempre estiveram lá, os lugares também assim como as histórias que margeiam suas terras e águas; as pessoas de fora geralmente é que não as percebem.

$\mathrm{Na}$ arqueologia, ao nomear um lugar de sítio arqueológico, pressuponho nesse lugar a habitação de memórias, histórias e experiências. Como explicarei, nem sempre esses lugares possuem o entendimento convencional do

9 Em especial para a arqueologia, quando se estuda os envolvimentos das paisagens com as pessoas convencionalmente em tempos passados, o olhar dessa paisagem no presente "perderia" as transformações no decorrer do tempo, remetendo, desse modo, ao passado como uma única e homogênea forma do modelo absoluto de experiência humana (Johnston 1998). 
que é o arqueológico. Mas, do ponto de vista localizado, os lugares e sítios podem e carregam uma gama de sensações naqueles que vivem em seu entorno (Bezerra 2013, 2017, 2018). De maneira emblemática, os exemplos na arqueologia brasileira demonstraram essas relações das pessoas e de suas narrativas com lugares antigos, como os trabalhos de Fabíola Silva $(2009,2012)$ e Silva \& Garcia (2015) com o povo indígena Assurini, do Xingu. Nesses aspectos, pesquisas como a de Irislane Moraes (2012) nos apresentam as histórias de um antigo engenho escravocrata na margem do Rio Aproaga, na Amazônia paraense, que com o decorrer do tempo, passou a ser habitado pelas comunidades quilombolas que moram no seu entorno (Moraes 2012).

Trabalhos de autoras e autores indigenas nos mostram cada vez mais um debate que aproxima as relações entre materiais arqueológicos com as histórias que esses materiais carregam. Este é o caso das narrativas contadas por Copacãm Tschucambang (2015) ao analisar uma coleção de materiais líticos junto aos anciões da comunidade de seu povo Laklãnõ/Xokleng. Tschucambang (2015) afirma que a partir do início da "pacificação" indígena da região atual do estado de Santa Catarina, no sul do Brasil, a vida de muitas aldeias e das suas formas de lidar com o ambiente foram drasticamente alteradas. A partir das conversas com os mais velhos, ele pode contar que antes os deslocamentos ocorriam "de um lugar para outro em época de caça e coleta, às vezes deixando alguns dos seus objetos no local, por exemplo a mão de pilão e outros, pois sabiam que iriam retornar" (Tschucambang 2015: 42). Assim, é por meio da escuta dos mais velhos que ele pode pensar nesse modo que as coisas e as pessoas estavam intimamente ligadas aos seus tempos e lugares.

Da mesma maneira, Célia Corrêa Xakriabá (2018), em pesquisa na região norte de Minas Gerais, demonstrou os múltiplos usos que o território alcança quando entendido não somente como um pedaço de terra, mas também como elemento ligado diretamente as políticas corporais na percepção de sua ciênciaterritório. Xakriabá acentua que o barro, o genipapo ${ }^{10}$ e o giz são marcadores temporais do fazer epistemológico xakriabá e marcam o debate de uma educação que provoque uma memória territorializada, em que:

argumento que a história Xakriabá é’ marcada por três temporalidades: do barro, do Genipapo e do Giz. Três simbolos que contam sobre a nossa trajetória, inspirados em nossas raizes profundas. O periodo de aprendizado que denomino de barro representa um periodo em que não existia a presença da instituição escola, mas que já existia a educação indígena, transmitida pelo entoar da palavra, na oralidade. [...]

Genipapo, faço referência aos momentos rituais em que as nossas tradições se materializam em nossos corpos. $\mathrm{O}$ povo Xakriabá e o genipapo estabeleceu historicamente uma forte relação com as pinturas corporais, representando o fortalecimento da nossa identidade como um dos processos que configuram a nossa forma de fazer educação indígena (não na escola, mas em nosso cotidiano). [...]

Giz. Utilizo o giz para simbolizar a ressignificação da escola, a partir da nossa concepção de educação, fazendo frente à escola que chega como instituição externa, em um primeiro momento desagregadora de nossa cultura. Somos Xakriabá e, após muita luta, podemos construir narrativas em que contamos a nossa própria versão da história, respeitando os processos próprios de uma escola diferenciada, que não suprime o conhecimento e o modo de ser Xakriabá. O Giz é uma referência ao que chamamos de "amansamento da escola" (Corrêa Xakriabá 2018: 61-62).

São muitos os exemplos hoje que nos demonstram formulações comunitárias e coletivas de um fazer e perceber conhecimentos, tempos e espacialidades dinâmicas para além da gramática acadêmica, como nos convida Célia Xakriabá (2018).

Já na região amazônica, Jaime Xamen Wai Wai (2017) discute como ocorreu a ocupação

10 A própria autora marca a palavra genipapo, com g, um neologismo para demonstrar que ele está com as "gentes". 
e qual foi a interpretação dos mais velhos nas aldeias Inajá e Mapuera, no rio Trombetas, no que diz respeito à chamada cerâmica konduri. Ele acentua a importância de conhecer os lugares (sítios) dos quais existem materiais dos antigos wai wai, feitos a partir da interação dos pajés conhecedores das rezas e rituais. Sobre os lugares, ele afirma que os "relatos nos apontam que grupos atuais ocupam locais em que apresentam sítio arqueológico com vestígios de ancestrais. [...]" (Wai Wai 2017: 53). Em relação à mobilidade da ocupação desses lugares, Xamen descreveu, a partir da escuta dos mais velhos, o processo de mudança de morada esteva ligado à morte de alguém, além de outros fatores, voltava-se eventualmente para o lugar original ligado a pessoa morta apenas para obter alimento (Wai Wai 2017). Há aqui um modo de lidar com os processos de formação dos lugares em que mesmo quando "abandonados" são lembrados e, muitas vezes, mesmo quando suas interdições eram compreendidas, voltavam a ser ocupados ou reelaborados de tempos em tempos.

Nesse mesmo sentido, questões elencadas por Irislane Moraes (2012) nos demonstram como a abordagem de construção etnográfica para a pesquisa possibilitou um diálogo com as histórias dos pretos d'antes do Aproaga e reflexionou uma posição para sua prática arqueológica. No que diz respeito às relações percebidas em sua pesquisa, ela nos informa que "determinados lugares, objetos, artefatos e ruínas constituem um mundo sensível para as pessoas, se fazendo existir com diferentes materialidades sejam por suas texturas sons e cheiros" (Moraes 2012: 136). Com foco nos usos contextuais e relacionais dos lugares, a autora sustenta que eles não são só espaços, mas, em muitos casos, são também energias outras, do mesmo modo que objetos, artefatos ou coisas estão permeados de ausências ao visível (Moraes 2012).

Segundo Alejandro Haber, as relações locais de entendimento do corpus disciplinar da arqueologia deixam escapar "outras experiências, especialmente aquelas que sustentam relações localmente significativas entre a coisa e a palavra, são ativamente ignoradas ou são apropriadas sem serem reconhecidas" (Haber 2011: 13; tradução nossa). Entendo essa crítica e proponho respostas localmente significativas a partir das quais é explicitada a importância dos lugares que emergem nas explicações locais de seus próprios conhecimentos e nas questões epistêmicas sobre a relação dos lugares com as pessoas, as comunidades e os coletivos com os quais a arqueologia criticamente pode estar envolvida (Haber 2011).

Acompanhando o pensamento de Juliana Machado (2011, 2013) e de outros autores da arqueologia, como David \& Thomas (2008), e fazendo uso da noção de território elaborada por Zedeño (2008), ressalto a importância do movimento de refletir sobre a paisagem que transforma a disciplina ao permitir visualizar melhor o fenômeno. Quando se nota essa transformação, se entende que as "paisagens então deixaram de ser 'paisagens ambientais' para serem de fato "paisagens sociais" (Machado 2013: 78).

É nesse deslocamento do olhar que passa a considerar a paisagem como elemento social amplo e atuante, como acentuado por Machado (2013), que podemos talvez entender parte das atividades e das relações que estabelecemos não somente com a arqueologia, mas também com as próprias pessoas. A partir do que já foi dito, as abordagens atuais de construção da paisagem como um lugar socialmente carregado de relações que se estabelecem no decorrer do tempo se colocam em contraste com a noção anterior de paisagem e de natureza como simplesmente provedores de recursos. Com isso, pensar paisagens, lugares e territórios mobilizados enquanto corpos-territórios e memórias territorializadas, como apontou Célia Correa Xakriabá (2018), é uma maneira profunda de (re) entender esses espaços não mais como o ocidente estabeleceu, mas como corpos vivos.

Tomo como possível o entendimento dessas relações de saberes, pouco tateadas pela soberania e tirania do conhecimento ocidental, para fora do olhar da própria "disciplina" a pensar a arqueologia como uma prática indisciplinada (Haber 2017). Visto ser necessário pensarmos nas relações da ausência do visível discutidas por Irislane Moraes (2012), quando queremos acessar lugares, paisagens e histórias 
que não são as dos próprios arqueólogos é preciso, antes de tudo, respeitarmos e entendermos as lógicas das comunidades com as quais estamos ligados.

Nesse sentido, é preciso pensar nas potencialidades e nas formas não hegemônicas de descrever o que é arqueológico, bem como dos modos em que este se liga a uma série de relações múltiplas. Questionar a própria binaridade conceitual, como paisagens-lugares ou tangivelintangivel, a compreendendo a partir de um olhar situado e posicionado nos parece uma ferramenta de cunho metodológico que a arqueologia pode levar a sério de modo a transformar o regime único de pensar a razão e a temporalização no que diz respeito a coletivos, lugares e coisas.

\section{As coisas e as histórias na Ilha do Pará, Afuá, foz do rio Amazonas}

As histórias das coisas que irei contar são um quebra-cabeça de narrativas, ou seja, são como os fragmentos de louças que teimosamente reaparecem para lembrarmos das existências de tempos materiais. Elas habitam as margens do rio Furo Seco, na Ilha do Pará, um braço do rio Amazonas localizado na parte centro sul da Ilha, com seus rios menores tais como o Tiojupá, o Água Preta e o Mará. Porém, essas múltiplas histórias não aparecem nem em livros didáticos da escola local, nem em jornais, nem mesmo nas revistas. Os rastros dos seus passados estão principalmente na presença oral das e dos moradores da Ilha do Pará e em suas coisas. Elas e eles me relatam, por meio das nossas conversas, que fazia bastante tempo que a ilha começou a ser habitada por pessoas que vinham de distintos lugares.

Um desses relatos mais reforçados é associado à Cabanagem, revolta contra o poder imperial que ocorreu na extensão geográfica do que se chamava de Grão-Pará durante os anos 1835-1840, que foi realizada por camadas de populações massivamente indígenas e negras (Pacheco 2016; Ricci 2006). Segundo as e os moradores da Ilha do Pará, na "época dos cabanos" muitas embarcações desconhecidas possivelmente passaram pela ilha, enquanto os cabanos se embrenharam pelas matas. Assim, emergiu um primeiro lugar-memória nessa minha conversa inicial sobre a história da Ilha do Pará, os lugares de um tempo em que "as pessoas se escondiam na mata".

Contam que eram nesses lugares e tempos que muitas dessas pessoas faziam suas moradas. Sobre as ocupações indígenas mais antigas, alguns moradores "veteranos", mais velhos, dizem que não chegaram a conhecê-los, mas que sabiam que existiam e que eram "muito de antigamente".

Segundo os entendimentos locais, havia algumas pessoas que apareciam de vez em quando em sonhos e para algumas crianças. Nesses sonhos, essas pessoas escondiam coisas de valor ${ }^{11}$ na rama das árvores ou as enterravam. Nem sempre essas histórias combinam-se com os registros arqueológicos convencionais ${ }^{12}$. Por meio desses sonhos ou no encontro com as crianças que brincavam por lugares próximos de capoeiras $^{13}$ (Fig. 2), tais pessoas ou entidades das matas ofereciam para as crianças coisas valiosas, porém alertavam que elas não deviam contar isso para ninguém, caso contrário esse bem oferecido sumiria.

11 Optei em escrever essas coisas como portadores de valor, pois muitas vezes elas aparecem como uma ideia de tesouro que poderia ser encontrado, mas não o é. Não são em si tesouros materialmente existentes, mas que devem ser entregues e aceitas de maneira específicas segundo as histórias sobre esses materiais. Misturam-se com as presenças de lugares encantados ou das pessoas escolhidas específicas para recuperar essas coisas.

$12 \mathrm{O}$ que aqui estou indicando é uma abertura para outras formas de vestígios, sobre as quais as relações das ocupações na ilha se tornam-se um eixo de discussão e não uma comprovação de algo.

13 Capoeira pode ser entendida como lugares semiabertos da mata, em que há uma intensa presença de ação física humana por meio das plantações ou da limpeza dos açaizais. 


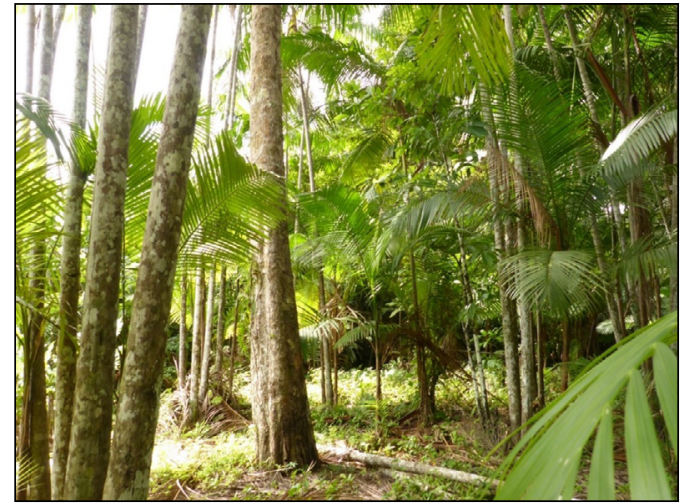

Fig. 2. Uma capoeira, lugar geralmente marcado por muitas palmeiras de açaí na ilha.

Fonte: Arquivo da pesquisa.

Essas coisas amazônicas aqui são compreendidas conforme o debate proposto por Márcia Bezerra (2017), Mariana Cabral (2016), Gabby Hartemann e Irislane Moraes (2018), no qual nos chamam a atenção para a relação existente com o sensível dessas coisas. Do mesmo modo, vem se ampliando o debate a partir da interpretação da ideia de coisas, ressaltando seja sua vida social seja suas relações críticas entre humanos e não humanos (Appadurai 1986; Hodder 2014; Ingold 2012; Latour 1994; Miller 2013). Coisa então seria uma definição para aquilo que está em aberto, para aquilo que ultrapassa a própria ideia de materialidade para ser pensado a partir do emaranhado de relações que a compõe um estado de vir a ser, material em formação, ser vivente (Ingold 2012).

Hartemann (2019), ao falar sobre "vida(s), movimentos(s), palavra(s): uma (teoria-tradução) exúrica das coisas" apontou para um conceito de coisa a partir da noção energética do orixá Exú, em diálogo com a concepção de coisa defendida por Ingold (2012) e inspirada pelas possibilidades de arqueologias com focos em ontologias não ocidentais (Alberti 2016). Para Hartemann, a coisa é concebida em uma "concepção da matéria como viva e em fluxo, bem como sua capacidade de movimento e de transformação, são necessárias para criarmos possibilidades de diálogos sobre (e com) essas coisas" (Hartemann 2019: 82).
Nesse entendimento, as coisas em seus teores mais abrangentes nos comunicam com os lugares e suas histórias, não estando separadas dos aspectos que compõe a vida e a sua organicidade. No meu trabalho etnográfico na Ilha do Pará, as coisas e as pessoas me dizem sobre tempos que nem sempre se podem entender por meio da tradução ocidental cronológica unilinear, como os tempos dos sonhos. Suas temporalizações e histórias não ocidentais aparecem em movimento, rasgando o elo presente-passado, de modo análogo à energia exúrica recontada e traduzida por Gabby Hartemann (2019), na qual "Exu é aquele que mata um pássaro ontem com a pedra que jogou hoje!” (Hartemann 2019: 70).

Longas histórias merecem longas explicações. Na Ilha, alguns lugares não podem ser visitados a qualquer hora do dia ou em dias específicos sem a devida proteção. Compreendese, por exemplo, que, em dia de algum santo cristão, não se pode trabalhar ou realizar algum tipo de esforço físico geralmente feito cotidianamente no cuidado das plantações ou em outros trabalhos que necessitam de aptidão física. Acredita-se que se a pessoa resolver desafiar ou "não respeitar o dia do santo", algo de ruim pode lhe acontecer.

De outras formas, também são contadas histórias de seres que habitam as matas, como a mãe do mato14, ser que que indica cuidado e proteção das matas e para quem se deve pedir licença para entrar na mata. As visagens são entidades que, na maioria das vezes, possuem a forma humana, mas que não participam do mesmo plano material que as pessoas, podendo ser comparadas como "almas penadas". Elas não são cotidianamente vistas e nem "cultuadas", sendo geralmente temidas, pois podem trazer alguma maleficio à saúde de quem entrar em

14 Para o antropólogo brasileiro Carlos Fausto (2008), a categoria sociocosmológica de "dono ou mestre", por meio de leituras de etnografias com distintas etnias e línguas indigenas amazônicas, acenta que nesses distintos contextos a categoria dono-mestre aparece muitas vezes associada a "um mundo de múltiplos domínios. Esses domínios são constitutivos da estrutura do cosmos, de tal modo que um dos pressupostos a reger a ação humana sobre o que chamaríamos de mundo natural é o de que tudo tem ou pode ter um dono" (Fausto 2008: 339, grifo do autor). 
contato com elas. Os encantados são outros modos de presenças que estão em vários lugares, como na beira de rios e nas clareiras no meio da floresta ou nas áreas mais afastadas de uma determinada moradia. Assim, as e os habitantes do Furo Seco contam que, apesar de alguns encantados já terem sido humanos, não todos o são, apesar de possuírem uma aparência próxima à corporalidade humana.

A potência de tais saberes amazônicos, por exemplo, carrega uma outra interpretação para o construto do que é natureza-cultura (Strathern 2014; Viveiros de Castro 2002). Ou seja, as coisas oriundas das diversidades de narrativas demonstram, entre outras presenças arqueológicas, uma historicidade que intercruza essas duas categorias. Desse modo, como contar a história da Ilha sem mencionar essas muitas pessoas "que se escondiam no mato antigamente", as quais hoje em dia aparecem nos sonhos de algumas pessoas oferecendo certas coisas? Seguir um percurso disciplinar de pesquisa que não nos deixa levar essas histórias a sério seria sobrepor o conhecimento arqueológico e histórico para essas narrativas que possuem uma grande importância nos discursos de conhecer situados.

Existe aqui uma espécie de manuseio de relações e de conhecimentos que estão além do "natural" e do "cultural". A tríplice ideia de coisa-tempo-pessoa é entendida como pontos que se interligam nas histórias contadas, ouvidas e praticadas por um conhecimento em forma de experiência. Suprir um desses pontos é lidar com apenas uma parte das vivências. Dessas vivências surgem escolhas pessoais, seja na possibilidade de temer algo, seja na de agir fora dessas histórias provocadas em sonhos ou nos percursos do dia a dia. Conforme apontado por Krenak (2019), entendo o sonho como uma instituição de saber que guia o aprendizado e o autoconhecimento, isto é, como uma interação contínua entre o mundo e as pessoas.

Interpreto então as ditas coisas mostradas nos sonhos como manifestações de visualizações não cotidianas da Ilha do Pará que aparecem em momentos, tempos, específicos e para pessoas específicas. O relato que me foi contado era que essas coisas possuíam um teor de encantadas, pois caso desrespeitadas as regras para serem vistas, logo desapareciam. Mais uma vez, elas possuem formas de aparições muito restritas àqueles que fossem escolhidos para visualizá-las ou sentir suas presenças. Similarmente, nessa retomada da memória local sobre tais "coisas valiosas", tomo como princípio o que Irislane Moraes ressaltou ao ir ao encontro dos lugares e coisas visagentas no Aproaga: "subentendi que visagens são tipos determinadas de aparições das coisas, animais, pessoas e objetos" (Moraes 2012: 173). Ou seja, tais coisas marcam a experiência social de um mundo outro, em que se conectam distintos modos de percepção ou sensibilidades diversas sobre ele.

Muitas vezes, essas declarações se apresentam por meio da memória sendo experienciada por determinadas contações de suas histórias, repassadas de geração para geração. Elas nem sempre estão ligadas a um momento presente da cronologia histórica ocidental, pois são contadas a partir de experiências vividas ou sentidas. Dessa forma, o tempo dos "homens que se escondiam nas matas" pode ser uma rememoração do período de fugidos conhecido como a Revolta da Cabanagem, mas também podem ser de outras pessoas e seres que coabitam esses mesmos lugares e paisagens.

\section{"De primeiro não era assim": ouvindo os mais velhos}

Em todo o processo dessa pesquisa, foi utilizado um modo de aprendizagem junto as pessoas locais que é o de "ouvir os mais velhos". Esse ato significa cumprimentar e dar ouvidos aos mais velhos, compreendidos como as pessoas que mais sabem. É uma falta de educação, por exemplo, interferir ou interromper de maneira intencional uma conversa em que duas pessoas mais velhas estão em diálogo; é preciso escutálas. Foi a partir dessas escutas e das múltiplas relações com a Ilha que eu consegui aprender com o senhor Edilson (Fig. 3), senhor de olhos cansados, mas de sorriso alegre que me recebeu em sua casa para uma conversa. Ele me contou que morava há mais de quarenta anos na beira do rio Água Preta, onde construiu família e fez casa. 


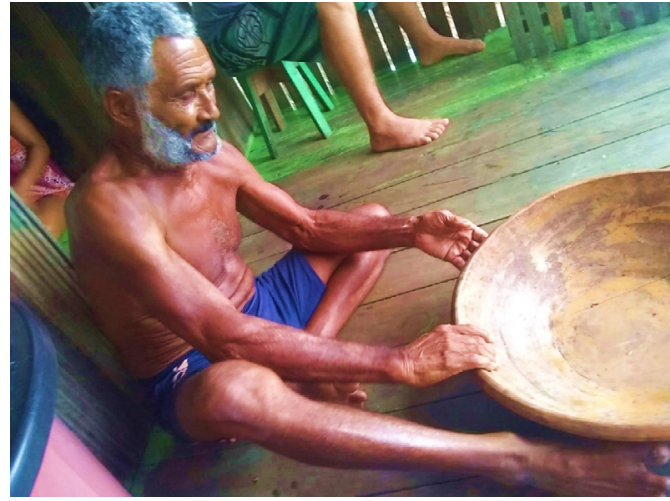

Fig. 3. Seu Edilson contando suas histórias, eu, seus netos ao redor e as pessoas sua nora e filho em sua volta o ouvíamos.

Fonte: Arquivo da pesquisa

Apontando-me para onde o rio começava e onde terminava suas terras, disse também que desde criança a sua mãe havia herdado aquela parte de terra dos pais dela, seus avós, sendo ele um dos moradores mais antigos. Ele sabia me dizer os lugares que antigos parentes, como a sua mãe, moravam, nomeando como "ficava mais para perto da boca do [rio] Mará" ou "a gente foi ficando aqui pelo [rio] Água Preta porque era melhor". Segundo ele, as antigas casas eram marcadoras desses elementos distintos de ocupação dos lugares, com seus grandes salões, onde se fazia alguma ladainha, reza ou festa de santo. Nostalgia e saudades se misturavam na sua fala, quando trazia à tona essas suas lembranças. Suas recordações, por sua vez, relampejavam as moradas no Rio Água Preta, as quais foram expostas nesse mesmo relampejar:

Sempre morando aí, nossa morada era um barracão, casarão porrudo [grande], fazia festa... fazia festa nesse tempo perto do natal de menino deus como chamavam, ai fazia uma mesa dos inocentes que a minha mãe dava para as crianças, ai depois das crianças vinha as dos adultos, ai depois dava umas horas tinha ladainha e depois vinha uma festa. Era assim que eles faziam né, fui desde pequeninho criado assim, nesse terreno... (Seu Edilson, fevereiro, 2020)
Mais uma vez, mais coisas emergiram na relação entre as distintas modalidades temporais. Seu Edilson apareceu para mim, indicado pelos próprios moradores da comunidade em 2019, quando iniciei a primeira etapa desse diálogo. Ele é um excelente contador de histórias em, por isso, faz questão de ressaltar como os tempos haviam mudado por ali pela ilha, me dizendo que agora estava tudo diferente. Sentados no pátio, em um final de tarde com a maré alta, seu Edilson de repente entra em sua casa para me mostrar como as coisas eram antigamente. Eis que ele reaparece em seguida e me mostra suas coisas, enquanto fala sobre um alguidar e uma peneira, demonstrando como antigamente se fazia açaí.

Seu Edilson: Seu moço, de primeiro nós pegávamos muita coisa no mato, trabalhávamos demais também, hoje em dia não, está tudo mudado.

Autor: mas o senhor sabe me contar se antes tinha muita louça ou pote velho jogado por aî?

Seu Edilson: A gente tinha era e bem, deixa te mostrar como era que a gente fazia açaí (Janeiro, 2019).

Esse entendimento, por exemplo, me possibilitou compreender algumas transformações das técnicas materiais usadas para caçar, pescar e produzir açaí. Ao remeter as suas memórias, seu Edilson, morador conhecedor, demonstrou que "de primeiro" não eram assim. Esse entendimento temporal é continuamente reiterado nos diálogos locais e exibe as fissuras entre tempos de modos de fazer distintos dos percebidos atualmente, mas ainda vivos nas falas dos mais velhos.

Pouco se caça hoje em dia, pois alguns moradores dizem que não há muitos dos animais que eram caçados "antigamente", nesse tempo, "de primeiro". Práticas de caçar durante a noite, conhecidas como lanternagem, são exemplos dessa mudança. Antes, seu Edilson contou que era usada uma lamparina na ponta de uma superfície de madeira com mais ou menos meio metro de cumprimento e uma proteção que envolvia a luz da lamparina, fazendo o que ele me apresentou como "poronca". Era desse modo que 
"De primeiro não era assim": histórias, paisagens e as coisas da Ilha do Pará, Afuá, Amazônia

R. Museu Arq. Etn., 36: 109-126, 2021.

se iluminava para caçar durante a noite. Hoje, quando pessoas fazem lanternagem, geralmente usam lanternas, ligando o próprio nome da coisa para sua prática.

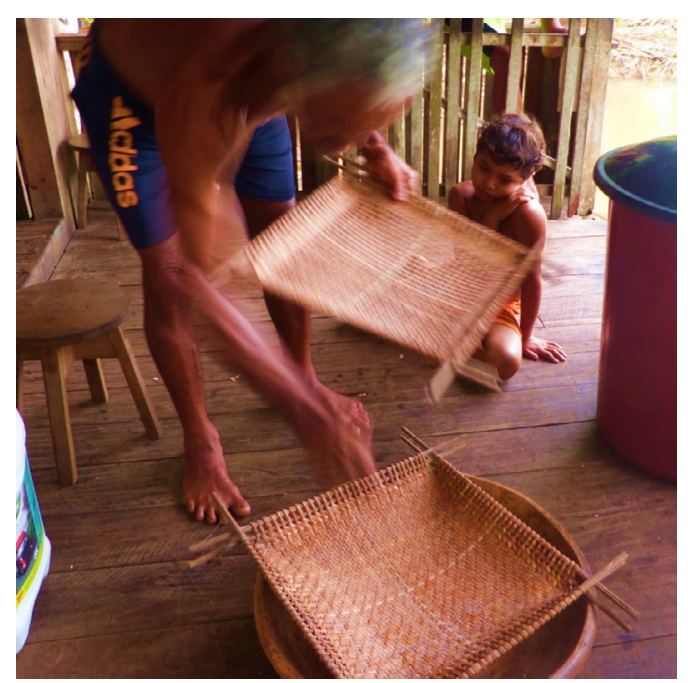

Fig. 4. Seu Edilson me demonstrando como se fazia açaí e contando suas histórias.

Fonte: Arquivo da pesquisa.

O movimento de demonstração do seu Edilson da feitura do açaí de antigamente (Fig.4) em uma peneira, me conectou a outro tempo, aquele anterior à chegada das máquinas movidas a eletricidade dos motores que produzem energia ou das baterias carregadas com placas solares. Nesse sentido, as pessoas e as histórias da Ilha do Pará se configuram como uma constante presença entre os tempos de antes e os de agora. Entretanto, esse antes e agora não aparecem como estanques e separados em diferentes momentos, "parados no tempo", mas sim como um momento de mudança que possibilita entender diferentes acontecimentos.

Como demonstra Ailton Krenak (2019), crítico dos atuais avanços das noções capitalistas de humanidade e da falsa divisão de natureza e de social para as pessoas indígenas, exemplificou muito bem o embate desses modos de compreensão do mundo ao narrar uma história, na qual diz:
Li uma história de um pesquisador europeu do começo do século XX que estava nos Estados Unidos e chegou a um território dos Hopi. Ele tinha pedido que alguém daquela aldeia facilitasse o encontro dele com uma anciã que ele queria entrevistar. Quando foi encontrála, ela estava parada perto de uma rocha. O pesquisador ficou esperando, até que falou: "Ela não vai conversar comigo, não?". Ao que seu facilitador respondeu: "Ela está conversando com a irmã dela". "Mas é uma pedra." E o camarada disse: "Qual é o problema?" (Krenak 2019: 10)

Para Krenak (2019), toda a nossa natureza está ocupada ou, melhor dizendo, a natureza não é matéria inerte ou fora das circulações humanas. Todos os seus lugares possuem donos, porque os sentidos de humanidade e de vida estão grudados ao significado do que seja natureza, quando esta não é vista como algo exterior, separada de nós, mas como algo junto de nós, conosco. Aqui a pedra é mais do que uma pedra, é presença corporificada de sentidos humanos. As gentes, como diz Ailton, que estão com essa "natureza" parecem estarem agarradas com a terra, parecem se alimentarem dessa terra, na qual as suas memórias possuem vínculos ancestrais (Krenak 2019).

Dessa forma, ao entender a arqueologia nas comunidades da Ilha do Pará a partir dos sentidos atribuídos às coisas, lugares e paisagens, tais elementos me remetem a um presente alimentado por narrativas que descentralizam o passado como algo simplesmente cronológico, que já não existe mais. Assim, o tempo é reinventado por meio das coisas e das pessoas. Junto deles estão os lugares, havendo um fluxo constante de relações. Ao pensar esses fluxos, lembro-me de Estar vivo: ensaios sobre movimento, conhecimento e descrição, escritos de Tim Ingold (2015), nos quais o antropólogo nos apresenta perante suas inúmeras observações sobre as substâncias, Terra e meio, em que destaco o trecho a seguir:

Em vez de pensar no mundo habitado como composto dos hemisférios mutuamente exclusivos do céu e da Terra, separados pelo chão é preciso assistir [...] aos fluxos do vento e do tempo. Sentir 
o ar e sentar no chão não é fazer contato tátil externo com o nosso entorno, mas se misturar a ele. Nesta mistura, conforme vivemos e respiramos, o vento, luz e umidade do céu se ligam com as substâncias da Terra no contínuo forjar de um caminho através do emaranhado de linhas de vida que compõem a Terra (Ingold 2015: 179).

As múltiplas linhas que emaranham distintos lugares possibilitam também distintas histórias. As formas de lidar com a fluidez das memórias vivas da Ilha, como as das capoeiras, estão espalhados em uma série de significados. Atualmente as capoeiras não só servem como plantações de açaí, mas também são lugares em que há muitas castanheiras e outros tipos de árvores. A interdição de determinados lugares, por exemplo, sempre está carregada da energia que aquele lugar possui, associada as aparições já comentadas. É de conhecimento local que determinados espaços, como as capoeiras ou os lugares nos quais uma árvore de cacau surge no meio da mata, foram mexidos, que alguém esteve ali. $\mathrm{O}$ antropogênico dessas paisagens é ainda uma pequena parte das relações que conseguimos observar por meio de vestígios. Além disso, tais lugares são habitados, me contam os moradores, por passados humanos e por vários seres em tempos e lugares em terra ou nas águas.

Se tratando da Amazônia, e em especial de uma ilha, ao falar sobre o espaço reservado às águas cabe cuidado, visto que nas águas vivem uma diversidade de seres. De modo análogo, as distintas histórias sobre botos, cobras grandes e outras criaturas que habitam o fundo dos rios percorrem também as narrativas da Ilha. Ou seja, todos os lugares são ocupados por alguma energia, muitas vezes contada nas narrações que envolvem histórias como quando, durante a busca por alguma planta na mata, se avistou de relance um ser ou quando, ao tomar banho tarde da noite na beira do rio de modo descuidado, sofreu-se algum tipo de adoecimento. São lugares e seres carregados de vida, ou, como diz Ailton Krenak (2019: 24), são "alguma constelação de seres que querem continuar compartilhando a vida nesta casa comum que chamamos Terra”.
É nessa descrição em movimento que entendo as histórias que me são contadas. Elas estão como a corrente do rio Amazonas, sempre em movimento, sendo recontadas e apresentadas de diversas formas, mas, principalmente, materializadas. A presença da diversidade de entendimento social e histórico dessas narrativas pode ser demonstrada materialmente sob a condição de testemunhas que atuam de maneira central na oralidade local. Como discutiu Machado (2011) em sua tese sobre as mulheres, as plantas e as redes de troca na Ilha de Caviana:

Não se trata, portanto, de um meio que os circunscreve, mas de um conjunto de relações efetivamente construidas entre humanos, plantas, animais e lugares, no sentido mais amplo do conceito de paisagem. O manejo ambiental praticado intensamente pelos ribeirinhos hoje é também uma forma de construção da memória e de afirmação de uma continuidade e está necessariamente imbricado nas relações de parentesco dos ilhéus (Machado 2011: 48).

Os lugares, as paisagens, os mundostempos e suas constelações memoriais (Ingold 2015; Krenak 2019; Machado 2011) costuram um apresentar material das histórias. Maré seca. Tempo que passa, mas não é passado. Eles assumem o movimento daquilo que toma posição; as paisagens da ilha se tornam percebidas e permeadas de uma "existência não pela presença no cotidiano, mas na ausência do visível" (Moraes 2012: 170).

Nessa perspectiva, os tempos de antigamente trazem consigo a força das narrativas das pessoas do rio Furo Seco. Pensar e relacionar esses passados, como uma entidade que simplesmente passou, não me parece fortuito nesse diálogo. É na tentativa de tentar evidenciar essas tensões que compreendo de antemão que os habitantes da ilha possuem um caráter ativo na ocupação dos lugares e da paisagem bem como elas e eles contam seu passado por meio de suas coisas materiais e da sua oralidade. Ao mesmo passo em que vivem em seu território e permanecem em relação de 
maneira prática e múltipla com o que chamo de coisa-tempo-pessoa.

Do outro lado dessa conversa, pode-se compreender essa tentativa de interpretação da ilha e de suas histórias, gentes e coisas como um modo de descentralizar a lógica única de entendimento sobre o que é o arqueológico bem como de ampliar o próprio conhecimento em que esse está operando, tensionando assim as noções convencionais da arqueologia (Cabral 2014).

\section{(In)concluindo}

Uma das intenções da arqueologia, desde suas primeiras coletas de materiais na foz amazônica, esteve ligada a apresentar objetos permeados por um apelo estético existente em potes, vasilhas, vasos adornados e pintados, ainda não conhecidos pela ciência do final do século XIX (Carmo dos Santos 2019). Do outro lado dessa longa história disciplinar, para mim, ouvir e entender como as comunidades que habitam as beiras dos rios da Amazônia visualizam as coisas arqueológicas e o seu redor torna-se de extrema importância. Pois, no decorrer da história da região, lidamos com uma dimensão de pessoas que estiveram a habitar o lugar em múltiplos modos de viver e de lidar com as paisagens, com os tempos e suas transformações (Machado 2014).

As escutas e conversas realizadas na Ilha do Pará me fizeram levar a sério a capacidade de vazar as condições interpretativas da arqueologia, ao não lidar apenas com uma ideia convencional de vestígio material passado. Aprender com as comunidades e as pessoas com as quais estamos dialogando tem sido um passo necessário e importante no compreender o que é o arqueológico e qual o papel social de arqueólogas e arqueólogos enquanto mediadores nas intervenções políticas presentes e nos distintos modos de entender e estar no mundo e com o mundo.

Articular uma compreensão etnográfica sobre as coisas em múltiplas temporalidades e sobre a relação das pessoas com seus lugares é estar atento às diferentes formas de relações explicativas, com base em uma epistemologia localmente referenciada e amazônica. As histórias que pairam sobre as memórias das pessoas que habitam a ilha e os materiais que emergem de suas explicações sempre estão em relação com uma diversidade de fatores. Eles variam desde lugares aonde não podemos ir por poderem ter visagem e outras entidades espirituais nem sempre visíveis até histórias daqueles que foram encantados e adoeceram ou se perderam no "mato" (a floresta), pois não ouviram ou não se protegeram - outros fatores incluem ainda as narrativas sobre os outros seres que habitam os fundos dos rios. É preciso ter cuidado: ignorar esses aspectos tão importantes nas ontoepistemologias é uma forma de reproduzir violências coloniais que praticaram no passado disciplinar da arqueologia e que são presentes e sentidas em mentes, corpos e seres não hegemônicos até hoje.

Na Ilha do Pará, essas histórias também podem ser lidas pelas perspectivas das chamadas "outras" ou "novas" ontologias (Alberti 2016). Mas, para nós oriundos da Amazônia, essas histórias não são novas: elas são sempre "lidas" e apresentadas em diferentes planos e contextos, e relatam os aspectos nada naturais das relações que estabelecemos com os lugares que habitamos ou com as cabeceiras dos rios em que não habitamos.

De modo muito sintomático, elas nos demonstram uma relação com o que está vivo e latente em uma verdadeira maneira de existir e de saber. O conhecimento mobilizado aqui em forma de uma explicação acadêmica sobre as coisas tem me ajudado a entender as possibilidades de questionar o que mais nós não sabemos, o que pode ser arqueológico e o que pode vir a ser. Nesses sentidos, nessa superfície de coisas espalhadas, é que caminhamos na Amazônia (Bezerra 2018) numa mistura de relações e apresentações de experiências que poucas vezes serão lidas fora da compreensão moderna ocidental europeia de existência, nas próprias maneiras de lidar com nossa vida-saber.

As incompletudes desse fazer são muitas e, por isso, elas permanecem em aberto, como o movimento do vento que ronda as ilhas da foz amazônica. Estar em movimento tem sido um rastro e uma metodologia que orienta 
minha relação em visualizar outras maneiras de pensar a arqueologia. Nesta discussão, tentei, no decorrer dessas palavras, trazer reflexões sobre aspectos relativos à noção de paisagem, discutidas por disciplinas como geografia e a própria crítica conceitual de paisagem, para os campos da arqueologia e antropologia. Desse modo, a abordagem metodológica começa e transcende a noção de etnografia que pesquisas em arqueologia vêm desenvolvendo com comunidades na Amazônia brasileira. Assim, acentuei, a partir da etnografia e arqueologia, pontos possíveis para pensar outras presenças arqueológicas, os muitos significados dos lugares, paisagens e dos tempos- coisaspessoas surgidos a partir do meu estudo com comunidades na foz do Rio Amazonas.

Retornando às palavras de Alejandro Haber (2011), ao afirmar que "a arqueologia se baseia em categorias abstratas e externas para posteriormente confirmar sua visão da ação social passada em termos de abstração e externalidade" (Haber 2011: 119; tradução nossa), torna-se necessária nossa compreensão dos discursos em que a arqueologia se envolve no decorrer da sua prática. Já não podemos e nem devemos nos envolver dentro de uma redoma de neutralidade de ciência. É preciso então intervir nessa externalidade disciplinar apontada e ir além desse modo único que a arqueologia e outras formulações disciplinares acionam, ao criar abstrações supostamente universais e que contam suas histórias unilaterais. Para que assim, quem sabe, possamos pensar um outro fim para esse mundo, ou, um outro mundo para novos fins.

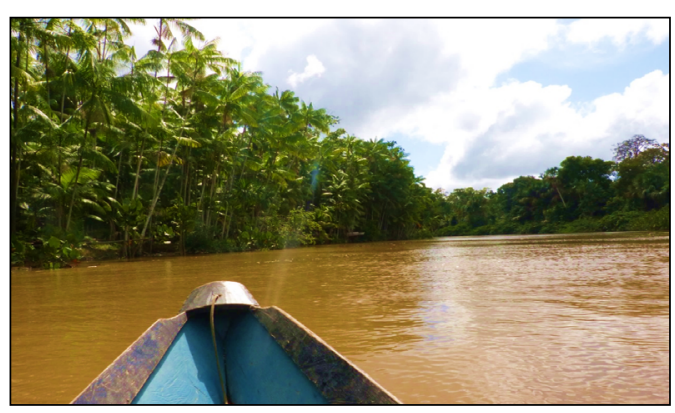

Fig. 5. Seguir viagem... pelas marés de histórias, guio uma canoa pelo Rio Mará afluente do Rio Furo Seco, Foz do Rio Amazonas.

Fonte: Arquivo da pesquisa.

\section{Agradecimentos}

Agradeço as pessoas que me contaram as suas histórias e me permitiram escrever elas nesse texto: às gentes da Ilha do Pará e, em especial, a seu Edilson e meu avô Hilton. Sou grato a minha mãe, Valdeia Silva do Carmo e meu pai Aloelson Rodrigues dos Santos por sempre me lembrar de onde viemos. Agradeço Gabby Hatermann por ter lido e chamado minha atenção para muitos dos pontos aqui discutidos, e a Iris Moraes pelas conversas e a inquietações com esse mundo. Agradeço também minha orientação afetuosa com Mariana Petry Cabral. Aos ancestrais. Axé!

SANTOS, Q. C. "At First, it wasn't like that": stories, landscapes and things from Pará Island, Afuá, Amazon. R. Museu Arq. Etn., 36: 109-126, 2021.

Abstract: Based on ethnographic archaeology, this study seeks to point how people living on the Island of Pará, Afuá, a region bordering the mouth of the Amazon River, relate to their landscapes, places and things and how, based on these elements, they elaborate narratives about their own temporality. Thus, this article intend to tension the understanding and practices related to the archaeological disciplinary field, by local knowledge and archaeological presences, thus contributing to current discussions that provoke a close relationship between ethnographic studies and archaeology in and of the Amazon.

Keywords: Archaeology; Ethnography; Things; Histories; Amazon. 
"De primeiro não era assim": histórias, paisagens e as coisas da Ilha do Pará, Afuá, Amazônia

R. Museu Arq. Etn., 36: 109-126, 2021.

\section{Referências bibliográficas}

Adichie, C.N. 2019. O perigo de uma história única. Companhia das Letras, São Paulo.

Alberti, B. 2016. Archaeologies of Ontology. Annual Review of Anthropology 45: 163-179.

Appadurai, A. 1986. The social life of things: commodities in cultural perspective. Cambridge University Press, Cambridge.

Barreto, C.; Lima, H.; Betancourt, C. (Orgs.). 2016. Cerâmicas Arqueológicas da Amazônia: rumo a uma nova síntese. IPHAN, Belém.

Bezerra, M. 2013. Os sentidos contemporâneos das coisas do passado: reflexões a partir da Amazônia. Revista de Arqueologia Pública 7(1): 107-122.

Bezerra, M. 2017. Teto e Afeto: sobre as pessoas, as coisas e a arqueologia na Amazônia. GK Noronha, Belém.

Bezerra, M. 2018. O machado que vaza ou algumas notas sobre as pessoas e as superfícies do passado presente na Amazônia. Revista Latino-Americana de Arqueologia Histórica 12(2): 51-58.

Cabral, L.O. 2000. A paisagem enquanto fenômeno vivido. Geosul 5: 34-45.

Cabral, M.P. 2014. No tempo das pedras moles: arqueologia e simetria na floresta. Tese de doutorado. Universidade Federal do Pará, Belém.

Cabral, M.P. 2016. Entre passado e presente: arqueologia e coletivos. Teoria e sociedade 24(2): 76-91.

Carmo dos Santos, Q. 2019. O tempo e a arqueologia: uma narrativa científica sobre o passado na Amazônia por meio das coisas arqueológicas ao final do século XIX. Temporalidades Revista de História 11(1): 84-99.

Castañeda, Q.E. 2008. The "Ethnographic Turn”. Archaeology: research positioning and reflexivity $\mathrm{i}$ Ethnographic Archaeologies. In: Castañeda, Q.E.; Matthews, C.N. (Eds.). Ethnographic Archaeologies: reflections on stakeholders and Archaeological practices. Altamira Press, Plymouth, 25-61.

Certeau, M. 1998. A Invenção do Cotidiano: Artes de Fazer. Vozes, Petrópolis.

Correa Xakriabá, C.N. 2018. O Barro, o Genipapo e o Giz no fazer epistemológico de Autoria Xakriabá: reativação da memória por uma educação territorializada. Dissertação de mestrado. Universidade de Brasília, Brasília.

David, B.; Thomas, J. 2008. Landscape Archaeology: Introduction. In: David, B.; Thomas, J. (Orgs.). Handbook of Landscape Archaeology. Left Coast Press, Walnut Creek, 27-43.

Engmann, R. 2019. Autoarchaeology at Christiansborg Castle (Ghana): Decolonizing knowledge, pedagogy, and practice. Journal of Community Archaeology \& Heritage 6: 204-219.

Evans, C.; Meggers, B. 1950. Preliminary Results of Archaeological Investigations at Mouth of the Amazon. American Antiquity 16(1): 1-9.

Fausto, C. 2008. Donos demais: maestria e domínio na Amazônia. Mana 14(2): 329-366.

Goeldi, E. 1900. Excavações archeologicas em 1895. Executadas pelo Museu Paraense no Littoral da Guyana Brazileira entre Oyapock e Amazonas. $1^{a}$ Parte: As cavernas funerárias artificiaes de Índios hoje extinctos no Rio Cunany (Goanany) $e$ sua cerâmica. Museu Paraense de História Natural e Ethnographia, Belém.

Guedes, A.P.L. 1898. Relatório sobre uma missão etnográfica e arqueológica aos Rios Maracá e Anauerá-Pucu (Guiana Brasileira), realizada pelo Tenente-Coronel Aureliano Pinto de Lima Guedes. Boletim do Museu Paraense de História Natural e Ethnografia 2: 42-63.

Haber, A. 2011. La Casa, Las Cosas y Los Dioses. Encuentro, Córdoba. 
Haber, A. 2017. Al Otro Lado del Vestigio: políticas del conocimiento y arqueología indisciplinada. Editorial Universidad del Cauca, Madrid; Ediciones del Signo, Buenos Aires.

Hamilakis, Y. 2009. Archaeological Ethnography: A Multitemporal Meeting Ground for Archaeology and Anthropology. Annual Review of Anthropology 40: 399-414.

Hamilakis, Y.; Anagnostopoulos, A. 2009. What is Archaeological Ethnography? Public Archaelogy 8: 2-3.

Haraway, D. 1995. Saberes localizados: a questão da ciência para o feminismo e o privilégio da perspectiva parcial. Cadernos Pagu 5: 7-41.

Hartemann, G. 2019. Voltar, contar e lembrar de Gangan: por uma arqueologia griótica afrodecolonial em Mana, Guiana. Dissertação de mestrado. Universidade Federal de Minas Gerais, Belo Horizonte.

Hartemann, G.; Moraes, I. 2018. Contar histórias e caminhar com ancestrais. Vestígios. Revista Latino-Americana De Arqueologia Histórica 12: 7-34.

Hodder, I. 2014. The entanglements of Humans and Things: A Long-Term View. New Literary History 45: 19-36.

Instituto Brasileiro de Geografia e Estatística. 2010. IBGE Cidades: Afuá. Disponível em: <https://bit. ly/2TxzJie >. Acesso em: 15/03/2018.

Instituto Brasileiro de Geografia e Estatística. 20172019. Portal de Mapas do IBGE. Disponível em: <https://bit.ly/2SIHRMx $>$. Acesso em: 19/08/2020.

Ingold, T. 2012. Trazendo as coisas de volta à vida: emaranhados criativos num mundo de materiais. Horizontes Antropológicos 29: 25-44.

Ingold, T. 2015. Estar vivo: ensaios sobre movimento, conhecimento e descrição. Vozes, Petrópolis.
Johnston, R. 1998. 'The Paradox of Landscape'. Journal of European Archaeology 1: 313-325.

Krenak, A. 2019. Ideias para adiar o fim do mundo. Companhia das Letras, São Paulo.

Latour, B. 1994. Jamais fomos modernos: ensaio de antropologia simétrica. Editora 34, Rio de Janeiro.

Lima, D.M. 1999. A construção histórica do termo caboclo. Sobre estruturas e representações sociais no meio rural amazônico. Novos Cadernos do Naea 2: 5-32.

Machado, J.S. 2009. Arqueologia e História nas construções de continuidade na Arqueologia Amazônica. Boletim do Museu Paraense Emílio Goeldi Ciências Humanas 4(1): 57-70.

Machado, J.S. 2011. Lugares de gente: mulheres, plantas e rede de trocas no delta Amazônico. Tese de doutorado. Museu Nacional, Universidade Federal do Rio de Janeiro, Rio de Janeiro.

Machado, J.S. 2013. História(s) indígena(s) e a prática arqueológica colaborativa. Revista de Arqueologia $S A B$ 26(1): 72-85.

Machado, J.S. 2014. Ilha de Caviana: Sobre as suas paisagens, tempos e transformações. Amazônica: Revista de Antropologia 6(2): 283-313.

Marandola Jr., E. 2013. Fenomenologia e pósfenomenologia: alternâncias e projeções do fazer geográfico humanista na geografia contemporânea. Geograficidade 3(2): 49-64.

Miller, D. 2013. Treco, troços e coisas. Zahar, Rio de Janeiro.

Moraes, I.P. 2012. Do tempo dos Pretos d'antes aos Povos do Aproaga: Patrimônio arqueológico e territorialidade quilombola no vale do Rio Capim. Dissertação de mestrado. Universidade Federal do Pará, Belém. 
"De primeiro não era assim": histórias, paisagens e as coisas da Ilha do Pará, Afuá, Amazônia

R. Museu Arq. Etn., 36: 109-126, 2021.

Murrieta, R.S. et al. 1999. Consumption and subsistence in three cabloco populations in Marajó Island, Amazon, Brazil. Human Ecology 27(3): 455-475.

Pacheco, A.S. 2016. Diásporas africanas e contatos afroindígenas na Amazônia Marajoara. Cadernos de História 17: 27-63.

Ricci, M. 2006. Cabanagem, cidadania e identidade revolucionária: o problema do patriotismo na Amazônia entre 1835 e 1840. Tempo: Revista do Departamento de História da UFF 11: 15-40.

Santos, M. 2006. A Natureza do Espaço: Técnica e Tempo, Razão e Emoção. Editora da Universidade de São Paulo, São Paulo.

Silva, F.A. 2009. Etnoarqueologia: Uma perspectiva Arqueológica para o Estudo da Cultura Material. Métis 8: 121-139.

Silva, F.A. 2012. O plural e o singular das arqueologias indígenas. Revista de Arqueologia SAB 25: 24-42.

Silva, F.A.; Garcia, L.W.G. 2015. Território e Memória dos Asurini do Xingu: Arqueologia colaborativa na T. I. Kuatinemu, Pará. Amazônica: Revista de Antropologia 7: 74-99.

Souza, A.C. 2005. Arqueologia da paisagem e a potencialidade interpretativa dos espaços sociais. Habitus 3: 291-300.
Strathern, M. 2014 O efeito etnográfico e outros ensaios. Cosac Naify, São Paulo.

Tschucambang, C. 2015. Artefatos arqueológicos no território Laklãnõ/Xokleng-SC. Trabalho de conclusão de curso. Universidade Federal de Santa Catarina, Florianópolis.

Tuan, Y.-F. 1983. Espaço e Lugar: a perspectiva da experiência. Difel, São Paulo.

Tuhiwai Smith, L. 2018. Descolonizando metodologias: pesquisa e povos indígenas. Editora da UFPR, Curitiba.

Viveiros de Castro, E. 2002. A inconstância da alma selvagem e outros ensaios de antropologia. Cosac Naify, São Paulo.

Wagley, C. 1957. Uma Comunidade Amazônica: um estudo do homem nos trópicos. Companhia Editora Nacional, São Paulo.

Wai Wai, J.X. 2017. Levantamento etnoarqueológico sobre a cerâmica Konduri e ocupação dos Wai Wai Na região da terra indígena Trombetas-Mapuera (Pará, Brasil). Trabalho de conclusão de curso. Universidade Federal do Oeste do Pará, Santarém.

Zedeño, M. 2008. The Archaeology of Territory and Territoriality. In: David, B.; Thomas, J. (Orgs.). Handbook of Landscape Archaeology. Left Coast Press, Walnut Creek, 210-217. 